\title{
Peroxisome proliferator-activated receptor $\gamma$ gene polymorphisms and restenosis in diabetic patients after stenting in coronary arteries
}

\author{
W. Koch ${ }^{1}$ V. Jung ${ }^{1}$ N. von Beckerath ${ }^{1}$ A. Schömig ${ }^{1}$ A. Kastrati ${ }^{1}$ \\ ${ }^{1}$ Deutsches Herzzentrum München and 1. Medizinische Klinik rechts der Isar, Technical University of Munich, Germany
}

\section{Diabetologia (2004) 47:1126-1127}

Unfortunately, the Greek letters alpha and gamma (as in $\alpha$-level and PPAR $\gamma$ ) appeared incorrectly as ' $a$ ' and ' $\mathrm{g}$ ' throughout the article. The printers apologise for this mistake.
Published online: 13 October 2004

C) Springer-Verlag 2004

DOI 10.1007/s00125-004-1520-6

The online version of the original article can be found at http://dx.doi.org/10.1007/s00125-004-1406-7

W. Koch (四)

Deutsches Herzzentrum München

and 1. Medizinische Klinik rechts der Isar,

Technical University of Munich, Germany

E-mail:wkoch@dhm.mhn.de

Tel.: +49-89-12182601, Fax: +49-89-12183053 